\title{
ENVELHECIMENTO FISIOLÓGICO DE TUBÉRCULOS DE BATATA PRODUZIDOS DURANTE O OUTONO E A PRIMAVERA E ARMAZENADOS EM DIFERENTES TEMPERATURAS $\left({ }^{1}\right)$
}

\author{
DILSON ANTÔNIO BISOGNIN $\left({ }^{2} *\right)$; SERGIO TONETTO DE FREITAS $\left({ }^{3}\right)$; AURI BRACKMANN $\left({ }^{2}\right)$; \\ JERÔNIMO LUIZ ANDRIOLO $\left({ }^{2}\right)$; ENGIL ISADORA PUJOL PEREIRA $\left({ }^{4}\right)$; DOUGLAS RENATO MULLER $\left({ }^{3}\right)$, \\ MAURÍCIO GUERRA BANDINELLI $\left({ }^{4}\right)$
}

\begin{abstract}
RESUMO
O armazenamento adequado dos tubérculos é muito importante para manter o equilíbrio da oferta de batata no mercado e para a obtenção de tubérculos-semente em adequado estádio fisiológico no momento do plantio. O objetivo deste trabalho foi determinar o efeito de diferentes temperaturas de armazenagem no envelhecimento fisiológico de tubérculos de três clones de batata produzidos durante o outono e a primavera. O experimento foi desenvolvido em um fatorial de três clones (Asterix, SMIJ461-1 e SMINIA793101-3) por quatro temperaturas de armazenamento $\left(4,8,12\right.$ e $25^{\circ} \mathrm{C}$ ) e duas épocas de plantio (outono e primavera) no delineamento experimental inteiramente casualizado, com quatro repetições. As avaliações foram em intervalos de 30 dias, do início até os 180 dias de armazenamento. O armazenamento refrigerado prolongou a dormência dos tubérculos, reduzindo o número de brotos e evitando o apodrecimento; as temperaturas de 4 e $8{ }^{\circ} \mathrm{C}$ impediram a brotação dos tubérculos produzidos no outono. A perda de massa fresca e a respiração dos tubérculos aumentaram com o tempo e a temperatura de armazenamento. A época de plantio altera o comportamento fisiológico dos tubérculos durante o armazenamento. $\mathrm{O}$ armazenamento à baixa temperatura $\left(4 \mathrm{e} 8^{\circ} \mathrm{C}\right)$ é eficaz para retardar o envelhecimento fisiológico.
\end{abstract}

Palavras-chave: Solanum tuberosum L., temperatura de armazenamento, perdas pós-colheita, respiração, batata-semente.

\section{ABSTRACT \\ PHYSIOLOGICAL AGING OF POTATO TUBERS PRODUCED DURING FALL AND SPRING GROWING SEASONS AND STORED UNDER DIFFERENT TEMPERATURES}

Adequate tuber storage is necessary to maintain a good availability of potato tubers in the market and to get seeds with adequate physiological age at planting. The objective of this work was to determine the effect of different storage temperatures on tuber physiological aging of three potato clones produced during fall and spring growing seasons. The experiment was carried out as factorial of three clones (Asterix, SMIJ461-1 and SMINIA793101-3) by four storage temperatures (4, 8, 12 and $25^{\circ} \mathrm{C}$ ) and two growing seasons (fall and spring) in a random design with four replications. At 30-day intervals, tubers were evaluated from the beginning to 180 days of storage. Cold storage increased dormancy period, reduced sprout number and kept health tubers. Tubers produced during fall season did not sprout at the storage temperatures of 4 and $8{ }^{\circ} \mathrm{C}$. Tuber fresh weight loss and respiration increased with storage period and temperature. Crop growing season changes tuber physiological aging during storage. Storage in low temperature $\left(4\right.$ and $8{ }^{\circ} \mathrm{C}$ ) conditions is efficient to slow down tuber aging.

Key words: Solanum tuberosum L., storage temperature, postharvest losses, respiration, seed potato.

$\left({ }^{1}\right)$ Recebido para publicação em 6 de julho de 2006 e aceito em 13 de setembro de 2007.

$\left({ }^{2}\right)$ Universidade Federal de Santa Maria (UFSM), Departamento de Fitotecnia. 97105-900, Santa Maria, RS. E-mail: dilsonb@smail.ufsm.br. $\left(^{*}\right)$ Autor para correspondência.

$\left.{ }^{3}\right)$ Programa de Pós-graduação em Agronomia, UFSM, Santa Maria, RS.

$\left({ }^{4}\right)$ Curso de Agronomia, UFSM, Santa Maria, RS. 


\section{INTRODUÇÃO}

A batata (Solanum tuberosum L.) é cultivada nas principais regiões produtoras do Rio Grande do Sul durante a primavera, entre agosto e dezembro e o outono, entre fevereiro e junho (BISOGNIN, 1996), o que resulta em picos de oferta de tubérculos no mercado. $\mathrm{O}$ armazenamento dos tubérculos sob temperatura adequada pode ser utilizado para regular a oferta do produto e reduzir as perdas pós-colheita (WURR e Allen, 1976). O armazenamento sob temperatura adequada pode controlar a dormência (HARKETT, 1981) e a brotação precoce de tubérculos-semente, evitando o esgotamento das reservas necessárias à emergência das plântulas (FonTes e Finger, 1999). Dessa forma, o armazenamento dos tubérculos é importante para o equilíbrio da oferta de batata no mercado e à obtenção de tubérculos-semente em idade fisiológica adequada no momento do plantio.

A idade fisiológica é resultante de mudanças bioquímicas ocorridas internamente nos tubérculos de batata (OLSEN, 2004), sendo caracterizada pelos estádios de dormência, dominância apical, plena brotação e senescência. A dormência é uma condição endógena regulada pelo balanço hormonal entre promotores e inibidores do crescimento, durante a qual os tubérculos não brotam mesmo em condições ambientais favoráveis (Bоотн e SHAw, 1990), ou seja, o progresso da idade fisiológica até o início da brotação depende da condição endógena do tubérculo (CALDIz et al., 2001). A baixa atividade metabólica dos tubérculos durante a dormência favorece a manutenção da massa fresca e reduz a ocorrência de podridões (CheOng e Govinden, 2004). Temperaturas baixas de armazenamento aumentam o período de dormência dos tubérculos (BURTON et al., 1992), e a brotação é mínima a $4{ }^{\circ} \mathrm{C}$ (Bоoth e Shaw, 1990). Tubérculos das cultivares Bintje, Radosa e Marijke brotaram aos 40 dias após a colheita, quando armazenados a $25{ }^{\circ} \mathrm{C}$, e aos 120 dias, quando armazenados a $4{ }^{\circ} \mathrm{C}$ (Fontes e Finger, 1999). Portanto, o armazenamento refrigerado pode ser utilizado para aumentar o período de dormência e manter a qualidade pós-colheita dos tubérculos.

Após o início da brotação, observa-se, em algumas cultivares, a dominância apical, caracterizada pela inibição da brotação das gemas laterais exercida pela gema apical. Atenuando-se a dominância apical, o crescimento vigoroso dos brotos laterais caracteriza o estádio de plena brotação, momento ideal para o plantio dos tubérculos. A senescência é caracterizada por uma ramificação intensa dos brotos, que leva ao esgotamento rápido das reservas seguido pela morte dos tubérculos (Bisognin, 1996). Durante o crescimento dos brotos ocorre aumento acentuado da respiração para suprir as necessidades energéticas, o que resulta na degradação de reservas, translocação de carboidratos, perda de água por transpiração e, conseqüentemente, perda de massa fresca dos tubérculos (Wiltshire e Совв, 1996). Portanto, o envelhecimento fisiológico está associado ao aumento da atividade metabólica dos tubérculos (CALDIZ et al., 1996) e à alteração do comportamento da brotação (CALDIZ et al., 2001), que resultam na perda de massa fresca (Wiltshire e СовB, 1996). O armazenamento dos tubérculos a $10^{\circ} \mathrm{C}$ resulta em uma perda de massa fresca de 1 a $2 \%$, durante o primeiro mês de armazenamento, de $0,8 \%$, até o início da brotação, e de 1,5\%, após a brotação dos tubérculos. Essas perdas podem ser minimizadas quando os tubérculos são armazenados a temperatura de $5{ }^{\circ} \mathrm{C}$ (Воотн е Shaw, 1990).

O objetivo foi determinar o efeito de diferentes temperaturas de armazenamento no envelhecimento fisiológico de tubérculos de três clones de batata, produzidos durante o outono e a primavera, para desenvolver estratégias de manejo pós-colheita.

\section{MATERIAL E MÉTODOS}

Os tubérculos foram produzidos em campo, na Fundação Estadual de Pesquisa Agropecuária (FEPAGRO), em Julio de Castilhos (RS), durante os plantios de outono (plantio em 9 de fevereiro e colheita em $1 .^{\circ}$ de junho) e primavera (plantio em 10 de agosto e colheita em 21 de dezembro) de 2004. O manejo das plantas e a dessecação da parte aérea com Paraquat, realizada 10 dias antes da colheita, seguiram as recomendações técnicas para o cultivo da batata (BIsognin, 1996). Após a colheita, os tubérculos foram transportados para o Departamento de Fitotecnia da Universidade Federal de Santa Maria (RS), para o manejo do experimento de armazenagem.

Os tubérculos foram submetidos ao processo de cura, que consistiu no armazenamento a $20^{\circ} \mathrm{C}$ por 15 dias para a suberização da periderme, antes de aplicar os tratamentos. O experimento foi desenvolvido em um fatorial de três clones (Asterix, SMIJ461-1 e SMINIA793101-3), quatro temperaturas de armazenamento $\left(4,8,12\right.$ e $\left.25^{\circ} \mathrm{C}\right)$ e duas épocas de plantio (outono e primavera) no delineamento experimental inteiramente casualizado, com quatro repetições de oito tubérculos cada uma. A umidade relativa do ar no interior das câmaras foi mantida em $85 \pm 5 \%$. Tanto as temperaturas como a umidade relativa do ar foram permanentemente monitoradas para garantir as condições preeestabelecidas dos tratamentos (Fockink, Panambí, RS). 
As avaliações dos tubérculos foram realizadas no início do experimento e aos 30,60, 90, 120, 150 e 180 dias de armazenagem. Foram determinados a porcentagem de tubérculos brotados e com sintomas de podridão, o número de brotos por tubérculo, a perda de massa fresca e a respiração. Tubérculos brotados e podres foram avaliados pela contagem de tubérculos com pelo menos um broto de $2 \mathrm{~mm}$ de comprimento e com sintomas de podridão respectivamente, sendo os valores expressos em porcentagem. Foram contados o número total de brotos de $2 \mathrm{~mm}$ de comprimento por tubérculo de cada amostra. A perda de massa fresca foi obtida pela diferença entre a massa fresca no início e no fim do armazenamento, sendo os valores expressos em porcentagem. A respiração foi obtida através do acondicionamento de aproximadamente $500 \mathrm{~g}$ de tubérculos de cada repetição em recipientes de $5 \mathrm{~L}$, os quais foram fechados hermeticamente. Após 8 horas, determinou-se a concentração final de $\mathrm{CO}_{2}(\mathrm{~mL}$ $\mathrm{kg}^{-1} \mathrm{~h}^{-1}$ ) do ar no interior dos recipientes, através de um analisador de gases (Agri-Datalog), sendo os valores utilizados para o cálculo da respiração. Os dados foram submetidos à análise de variância e as médias comparadas por teste de Duncan ou regressão polinomial, conforme o caso, a $5 \%$ de probabilidade de erro.

\section{RESULTADOS E DISCUSSÃO}

Pelo teste F, observaram-se diferenças significativas para a interação entre os fatores clone $\mathrm{x}$ época de plantio $\mathrm{x}$ temperatura de armazenamento para todas as variáveis analisadas, com exceção da porcentagem de tubérculos podres. A ocorrência de podridões durante o armazenamento foi observada apenas nos tubérculos armazenados a $25^{\circ} \mathrm{C}$. A média de podridão dos tubérculos produzidos durante a primavera foi de $33 \%$, aos 90 dias, e $46 \%$, aos 120 dias de armazenamento. Devido à alta porcentagem de tubérculos podres, os tubérculos armazenados na temperatura de $25^{\circ} \mathrm{C}$ foram avaliados somente até os 120 dias. A análise entre os fatores qualitativos mostrou, exceto para porcentagem de perda de massa fresca do clone SMIJ461-1, valores obtidos no plantio de primavera superiores aos de outono (Tabela 1).

A produção dos tubérculos na primavera resultou em maior porcentagem de tubérculos brotados e de número de brotos por tubérculo durante o armazenamento (Tabela 1). Para os três clones avaliados, os tubérculos produzidos durante o outono mantiveram-se dormentes até os 180 dias, quando armazenados nas temperaturas de 4 e $8{ }^{\circ} \mathrm{C}$ (Figura 1). Entretanto, à temperatura de $12{ }^{\circ} \mathrm{C}$ nos clones Asterix e SMIJ461-1, aos 90 dias e no clone SMINIA793101-3, aos 120 dias de armazenamento, havia $50 \%$ dos tubérculos com pelo menos um broto de $2 \mathrm{~mm}$ de comprimento. Na primavera, somente os tubérculos dos clones SMIJ461-1 e SMINIA793101-3, armazenados à temperatura de $4{ }^{\circ} \mathrm{C}$, mantiveram-se sem brotação até os 180 dias. Para a temperatura de $25{ }^{\circ} \mathrm{C}$, em $50 \%$ dos tubérculos do clone SMINIA793101-3 já havia brotação aos 30 dias de armazenamento.

Tabela 1. Médias de quatro temperaturas de armazenamento e seis avaliações para porcentagem de tubérculos brotados, número de brotos por tubérculo, perda de massa fresca, porcentagem de podridão e respiração de três clones batata cultivados no outono e na primavera de 2004. Santa Maria (RS), 2005

\begin{tabular}{|c|c|c|c|c|c|}
\hline $\begin{array}{l}\text { Clone } \\
\text { brotados }\end{array}$ & $\begin{array}{c}\text { Tubérculos } \\
\text { por }\end{array}$ & $\begin{array}{c}\text { Brotos } \\
\text { tubérculo }\end{array}$ & $\begin{array}{c}\text { Perda } \\
\text { de massa fresca }\end{array}$ & Podridão & Respiração \\
\hline & $\%$ & n. ${ }^{\mathrm{o}}$ & $\%$ & $\%$ & $\mathrm{~mL}$ de $\mathrm{CO}_{2} \mathrm{~kg}^{-1} \mathrm{~h}^{-1}$ \\
\hline & & & Plantio de outono & & \\
\hline Asterix & $29,8 \mathrm{~b} \mathrm{~B}^{*}$ & 0,62 a $B$ & $8,96 \mathrm{~b} \mathrm{~B}$ & 43,2 a $B$ & 0,95 с B \\
\hline SMINIA793101-3 & 27,6 b B & $0,45 \mathrm{~b} \mathrm{~B}$ & 9,58 a $\mathrm{B}$ & 51,8 a B & $1,05 \mathrm{~b} \mathrm{~B}$ \\
\hline SMIJ461-1 & 32,6 a B & 0,43 с B & 9,94 a $\mathrm{A}$ & 51,8 a B & 1,30 a $\mathrm{B}$ \\
\hline \multirow[t]{2}{*}{$\mathrm{CV} \%$} & 2,12 & 17,14 & 1,60 & 32,12 & 1,56 \\
\hline & & & lantio de primaver & & \\
\hline Asterix & 52,9 a $\mathrm{A}$ & 2,61 a $A$ & 11,07 b A & 82,3 a $\mathrm{A}$ & 4,00 с A \\
\hline SMINIA793101-3 & $48,1 \mathrm{~b} \mathrm{~A}$ & $2,09 \mathrm{~b} \mathrm{~A}$ & 14,84 a $\mathrm{A}$ & 88,6 a $A$ & 4,95 a $\mathrm{A}$ \\
\hline SMIJ461-1 & $38,0 \mathrm{c} \mathrm{A}$ & 0,96 с A & 8,57 с B & 82,3 a $\mathrm{A}$ & $4,39 \mathrm{~b} \mathrm{~A}$ \\
\hline $\mathrm{CV} \%$ & 3,71 & 10,11 & 3,35 & 28,92 & 2,75 \\
\hline
\end{tabular}

* Médias das quatro temperaturas de armazenamento e seis avaliações, seguidas pela mesma letra, minúscula entre clones (em uma mesma época) e maiúscula entre épocas de plantio (para o mesmo clone), não diferem pelo teste de Duncan a 5\% de probabilidade de erro. 

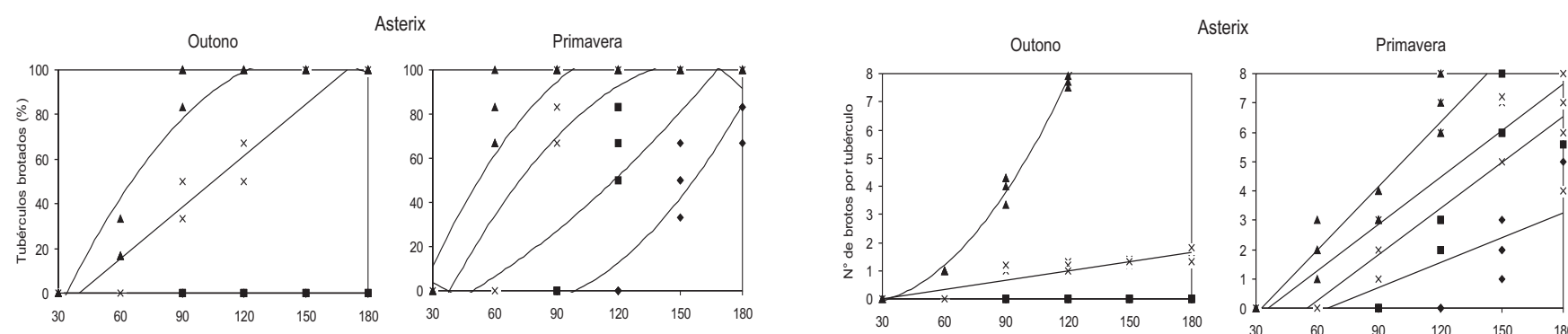

SMIJ793101-3
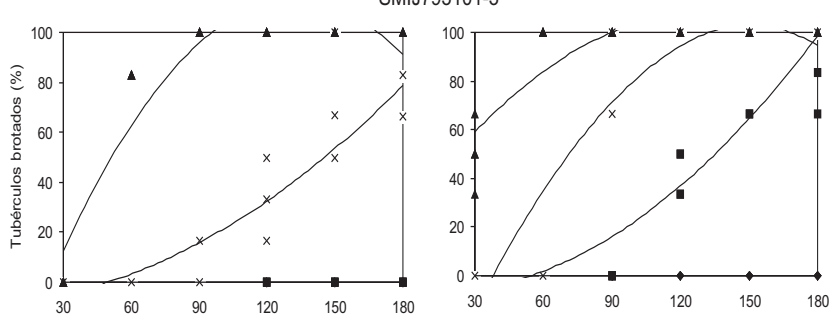

SMIJ461-1
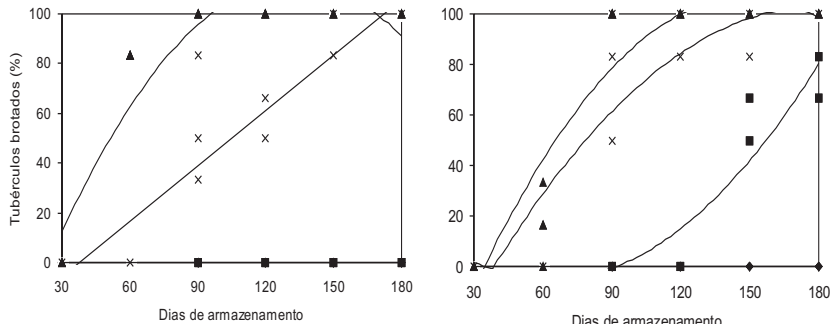

Figura 1. Porcentagem de tubérculos brotados dos clones Asterix, SMINIA793101-3 eSMIJ461-1 de batata armazenados em diferentes temperaturas durante 180 dias. Santa Maria (RS), 2005. Plantio de outono - Asterix: $4^{\circ} \mathrm{Ce} 8^{\circ} \mathrm{C} y=0 ; 12^{\circ} \mathrm{C} y=-30,847+0,7699 x R^{2}=0,92$; $25^{\circ} \mathrm{C} y=0,0301 x^{2}-2,0181 x+33,435 \mathrm{R}^{2}=0,98 ;$ SMINIA793101-3 $4{ }^{\circ} \mathrm{C}$ e $8{ }^{\circ} \mathrm{C} y=0 ; 12{ }^{\circ} \mathrm{C} y=-8,8727+0,06 x+0,0024 x^{2} R^{2}=0,82 ; 25{ }^{\circ} \mathrm{C} y=-$ $0,0368 x^{2}+6,084 x-149,39 \mathrm{R}^{2}=1 ; \quad \mathrm{SMI} 461-14{ }^{\circ} \mathrm{C}$ e $8{ }^{\circ} \mathrm{C} \mathrm{y}=0 ; 12^{\circ} \mathrm{C}$ $y=-28,352+0,7456 x R^{2}=0,89 ; 25^{\circ} \mathrm{C} y=-0,0368 x^{2}+6,084 x-149,39 R^{2}=1$. Plantio de primavera - Asterix $4{ }^{\circ} \mathrm{C} y=26,666-0,9881 x+0,0073 x^{2}$ $\mathrm{R}^{2}=0,92 ; 8{ }^{\circ} \mathrm{C} \mathrm{y}=-22,498+0,3432 \mathrm{x}+0,0023 \mathrm{x}^{2} \mathrm{R}^{2}=0,85 ; 12{ }^{\circ} \mathrm{C} \mathrm{y}=-$ $74,999+2,2321 x-0,0069 x^{2} R^{2}=0,85 ; 25^{\circ} \mathrm{C} y=-0,0324 x^{2}+5,555 x-137,49$

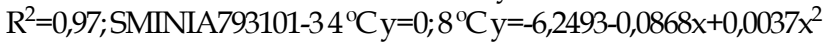
$\mathrm{R}^{2}=0,86 ; 12{ }^{\circ} \mathrm{C} \mathrm{y}=-8,8727+0,06 \mathrm{x}+0,0024 \mathrm{x}^{2} \mathrm{R}^{2}=0,82 ; 25^{\circ} \mathrm{C} \mathrm{y}=-$ $0,0278 x^{2}+4,1669 x-50,007 R^{2}=0,92 ;$ SMIJ461- $4{ }^{\circ} \mathrm{C} y=0 ; 8^{\circ} \mathrm{C}$ $y=19,998-0,7956 x+0,0063 x^{2} R^{2}=0,89 ; 12{ }^{\circ} \mathrm{C} y=-64,582+1,8675 x-$ $0,0052 x^{2} R^{2}=0,85 ; 25^{\circ} \mathrm{C} y=0,037 x^{2}-2,7783 x+50,013 R^{2}=0,97$.

O número de brotos por tubérculo aumentou com a temperatura de armazenamento, sendo os maiores valores obtidos a $25^{\circ} \mathrm{C}$ (Figura 2). A redução da temperatura de armazenamento retardou o início da brotação e diminuiu o número de brotos por tubérculo. Em todos os clones e temperaturas de armazenamento avaliados, houve aumento do número de brotos por tubérculo a partir do início da brotação, sendo que o número médio de brotos por tubérculo variou com o clone e a época de plantio (Tabela 1).
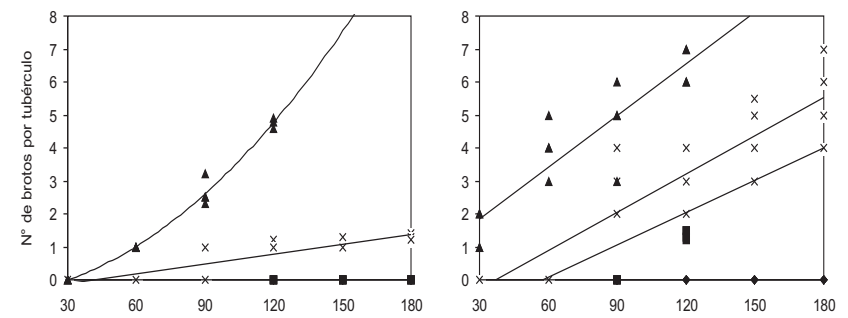

SMIJ461-1
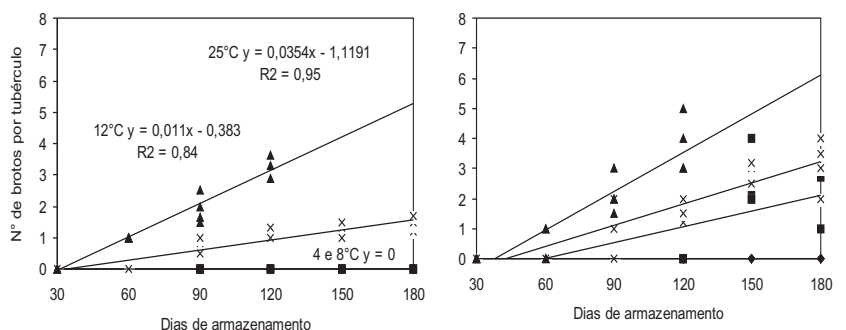

Figura 2. Número de brotos por tubérculo dos clones Asterix, SMINIA793101-3 eSMIJ461-1 de batata armazenados em diferentes temperaturas durante 180 dias. Santa Maria (RS), 2005. Plantio de outono - Asterix: $4^{\circ} \mathrm{C}$ e $8{ }^{\circ} \mathrm{C} y=0 ; 12{ }^{\circ} \mathrm{C} y=-0,315+0,0105 x R^{2}=0,82$; $25^{\circ} \mathrm{C} y=0,0622-0,0269 x+0,0008 x^{2} R^{2}=0,91 ;$ SMINIA793101-3 $4^{\circ} \mathrm{Ce} 8$ ${ }^{\circ} \mathrm{C} ; 12^{\circ} \mathrm{C} y=-0,325+0,0085 x R^{2}=68 ; 25^{\circ} \mathrm{C} y=-0,4549+0,0055 x+0,0003 x^{2}$ $\mathrm{R}^{2}=0,95 ; \mathrm{SMIJ} 461-14^{\circ} \mathrm{C}$ e $8{ }^{\circ} \mathrm{C} \mathrm{y}=0 ; 12^{\circ} \mathrm{C} \mathrm{y}=-0,383+0,011 \times \mathrm{R}^{2}=0,84$; $25^{\circ} \mathrm{C} y=-1,1191+0,0354 \times R^{2}=0,95$. Plantio de primavera - Asterix 4 ${ }^{\circ} \mathrm{C} y=-1,85+0,0283 \times R^{2}=0,63 ; 8^{\circ} \mathrm{C} y=-2,8667+0,0521 \times R^{2}=0,79 ; 12{ }^{\circ} \mathrm{C}$ $\mathrm{y}=-1,89+0,053 \times \mathrm{R}^{2}=0,75 ; 25^{\circ} \mathrm{C} \mathrm{y}=-2,375+0,0725 \mathrm{x} \mathrm{R}^{2}=0,92$; SMINIA793101-3 $4{ }^{\circ} \mathrm{C} y=0 ; 8{ }^{\circ} \mathrm{C} y=-1,875+0,0327 x R^{2}=0,83 ; 12{ }^{\circ} \mathrm{C}$ $\mathrm{y}=-1,4167+0,0387 \times \mathrm{R}^{2}=0,82 ; 25^{\circ} \mathrm{C} y=0,25+0,0525 \times \mathrm{R}^{2}=0,82 ;$ SMIJ $461-$ $14^{\circ} \mathrm{C} y=0 ; 8^{\circ} \mathrm{C} y=-1,0683+0,0177 x R^{2}=0,56 ; 12^{\circ} \mathrm{C} y=-0,995+0,0235 x$ $R^{2}=0,82 ; 25^{\circ} \mathrm{C} y=-1,625+0,0429 \times R^{2}=0,84$.

As condições ambientais características do plantio de primavera (temperatura e fotoperíodo crescentes) proporcionaram maior porcentagem de tubérculos brotados e maior número de brotos por tubérculo ao longo do armazenamento. Além disso, o aumento da temperatura de armazenamento acelerou a brotação dos tubérculos e incrementou tanto a porcentagem de tubérculos brotados quanto o número de brotos por tubérculos. Portanto, o fim da dormência dos tubérculos foi influenciado pela época de plantio e pela temperatura de armazenamento, ou seja, tanto a produção (plantio de primavera) quanto o armazenamento em temperaturas mais elevadas aceleraram a brotação dos tubérculos. No plantio de outono, tanto a temperatura de armazenamento de 4 
${ }^{\circ} \mathrm{C}$ quanto de $8{ }^{\circ} \mathrm{C}$ mantiveram os tubérculos em estádio de dormência durante os 180 dias, o que ocorreu somente com a temperatura de $4{ }^{\circ} \mathrm{C}$ quando os tubérculos foram produzidos na primavera. $\mathrm{O}$ armazenamento na temperatura de $25^{\circ} \mathrm{C}$ eliminou o efeito de época de plantio, o que pode ser utilizado por um curto período de tempo para estimular a brotação de tubérculos-semente para o plantio na próxima safra. No caso do armazenamento de tubérculos-semente para o plantio no ano seguinte, tubérculos produzidos durante o outono podem ser armazenados a $12{ }^{\circ} \mathrm{C}$ e na primavera nas temperaturas de 8 ou $4{ }^{\circ} \mathrm{C}$, devido ao menor período de dormência dos tubérculos. Essa redução da temperatura é necessária pelo fato de que no fim do armazenamento os tubérculos produzidos no outono e armazenados a $12{ }^{\circ} \mathrm{C}$ atingiram similar idade fisiológica daqueles produzidos na primavera já aos 90 dias, ou seja, houve uma redução de $50 \%$ no período em que os tubérculos poderiam ser armazenados somente por efeito de época de plantio.

A ampliação do período de dormência com a redução da temperatura de armazenamento tem sido verificada em outras condições de cultivo (Воотн e Shaw, 1990; Burton et al., 1992; Fontes e Finger, 1999). Os resultados deste trabalho indicam claramente que a época de plantio tem um grande efeito sobre o período de dormência e pode superar possíveis diferenças genéticas, o que deve ser considerado para o adequado manejo pós-colheita dos tubérculos. Temperatura e fotoperíodo crescentes no fim do ciclo diminuem o nível de dormência dos tubérculos (Beukema e VAn der ZaAG, 1979), o que acelera o envelhecimento fisiológico e reduz o tempo de armazenamento pós-colheita. O envelhecimento fisiológico dos tubérculos-semente leva à rápida e uniforme emergência (OLsen, 2004) e ao aumento da precocidade de tuberização e da colheita (AsIEDu et al., 2003). A colheita precoce pode ser uma alternativa para minimizar os efeitos das altas temperaturas do fim da primavera sobre o rendimento da batata no Rio Grande do Sul. As condições ambientais durante o cultivo, provavelmente, proporcionaram menor acúmulo de substâncias de reserva nos tubérculos cultivados no outono em relação aos cultivados na primavera (PASTORINI et al., 2003; NodA et al., 2004; ReYes et al., 2004). Esse menor acúmulo de reservas, combinado com baixas temperaturas de armazenamento $\left(4\right.$ e $\left.8{ }^{\circ} \mathrm{C}\right)$ resultaram em menor metabolismo dos tubérculos e, provavelmente, mantiveram relação hormonal capaz de inibir a brotação por maior período do que os tubérculos armazenados a $12{ }^{\circ} \mathrm{C}$ e $25^{\circ} \mathrm{C}$ em ambas as épocas de plantio (Suttle, 1995; Wiltshire e Совв, 1996).

A perda de massa fresca dos tubérculos aumentou com o tempo e a temperatura de armazenamento (Figura 3). O armazenamento à temperatura de $12{ }^{\circ} \mathrm{C}$ resultou em perdas de massa fresca entre $15 \%$ e $20 \%$. A perda de massa fresca foi ainda menor com o armazenamento nas temperaturas de 4 e $8{ }^{\circ} \mathrm{C}$. A respiração dos tubérculos aumentou com a temperatura de armazenamento (Figura 4); o armazenamento refrigerado proporcionou grande redução na respiração dos tubérculos em relação ao armazenamento a $25^{\circ} \mathrm{C}$. Comparado com os tubérculos produzidos durante o outono, o plantio de primavera resultou em maior respiração desde o início do armazenamento e, quando armazenados a 12 e $25^{\circ} \mathrm{C}$ tiveram perda de massa fresca e respiração mais elevadas.

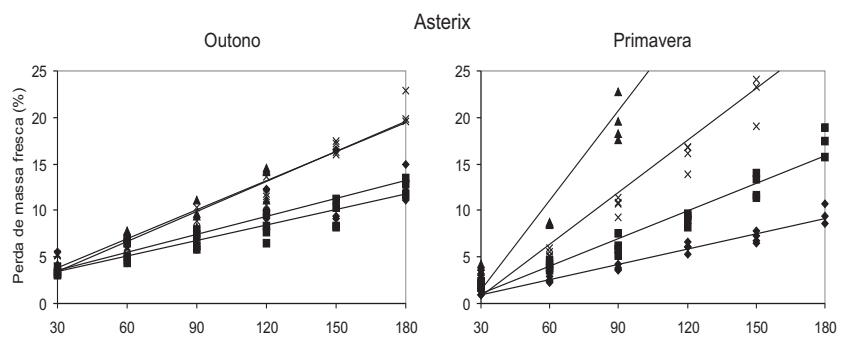

SMIJ793101-3
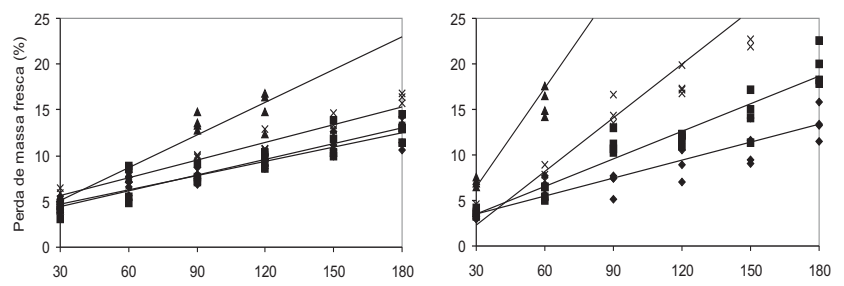

SMIJ461-1
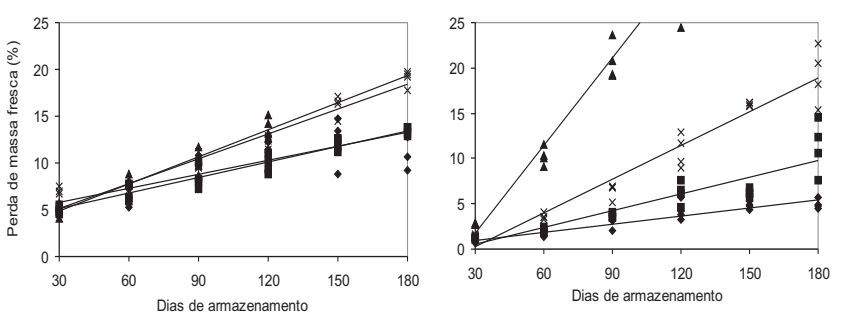

Figura 3. Perda de massa fresca de tubérculo dos clones Asterix, SMINIA793101-3 e SMIJ461-1 de batata armazenados em diferentes temperaturas durante 180 dias. Santa Maria (RS), 2005. Plantio de outono - Asterix $4{ }^{\circ} \mathrm{C} y=1,7137+0,0633 x$ $\mathrm{R}^{2}=0,80 ; 8^{\circ} \mathrm{C} \mathrm{y}=1,7177+0,0568 \times \mathrm{R}^{2}=0,88 ; 12^{\circ} \mathrm{C} \mathrm{y}=0,2628+0,1066 \mathrm{x}$ $\mathrm{R}^{2}=0,94 ; 25^{\circ} \mathrm{C} \mathrm{y}=0,7313+0,1039 x \mathrm{R}^{2}=0,93$; SMINIA793101-3 4 ${ }^{\circ} \mathrm{C} y=2,5795+0,0564 \times R^{2}=0,89 ; 8^{\circ} \mathrm{C} y=2,2586+0,0613 \times R^{2}=0,87$; $12^{\circ} \mathrm{C} y=3,0214+0,0701 \times R^{2}=0,92 ; 25^{\circ} \mathrm{C} y=1,07+0,1238 \times R^{2}=0,92$; SMIJ461-1 $4 \quad{ }^{\circ} \mathrm{C} \quad \mathrm{y}=3,5075+0,0558 \mathrm{x} \quad \mathrm{R}^{2}=0,72 ; \quad 8 \quad{ }^{\circ} \mathrm{C}$ $y=2,8125+0,0606 \times R^{2}=0,92 ; 12{ }^{\circ} \mathrm{C} y=2,0051+0,0924 \times R^{2}=0,94 ; 25$ ${ }^{\circ} \mathrm{C} y=1,4145+0,1027 x R^{2}=0,94$. Plantio de primavera - Asterix $4^{\circ} \mathrm{C} y=-0,5739+0,0535 x R^{2}=0,96 ; 8^{\circ} \mathrm{C} y=-1,5044+0,0957 \times R^{2}=0,95$; $12{ }^{\circ} \mathrm{C} y=-3,8889+0,1793 x R^{2}=0,94 ; 25{ }^{\circ} \mathrm{C} y=-5,9427+0,2971 x$ $\mathrm{R}^{2}=0,94$; SMINIA793101-3 $4{ }^{\circ} \mathrm{C} \mathrm{y}=1,2637+0,0675 \mathrm{x} \mathrm{R}^{2}=0,86 ; 8$ ${ }^{\circ} \mathrm{C} y=0,4008+0,1018 \times R^{2}=0,92 ; 12^{\circ} \mathrm{C} y=-2,8977+0,1914 \times R^{2}=0,95$; $25 \quad{ }^{\circ} \mathrm{C} \quad \mathrm{y}=-3,16+0,3486 \mathrm{x} \quad \mathrm{R}^{2}=0,96 ; \quad \mathrm{SMIJ} 461-1 \quad 4 \quad{ }^{\circ} \mathrm{C}$ $y=0,1007+0,0299 \times R^{2}=0,87 ; 8{ }^{\circ} \mathrm{C} y=-1,1249+0,0601 \times R^{2}=0,82 ; 12$ ${ }^{\circ} \mathrm{C} y=-2,8227+0,1192 \times R^{2}=0,94 ; 25^{\circ} \mathrm{C} y=-5,7082+0,2985 \times R^{2}=0,92$. 

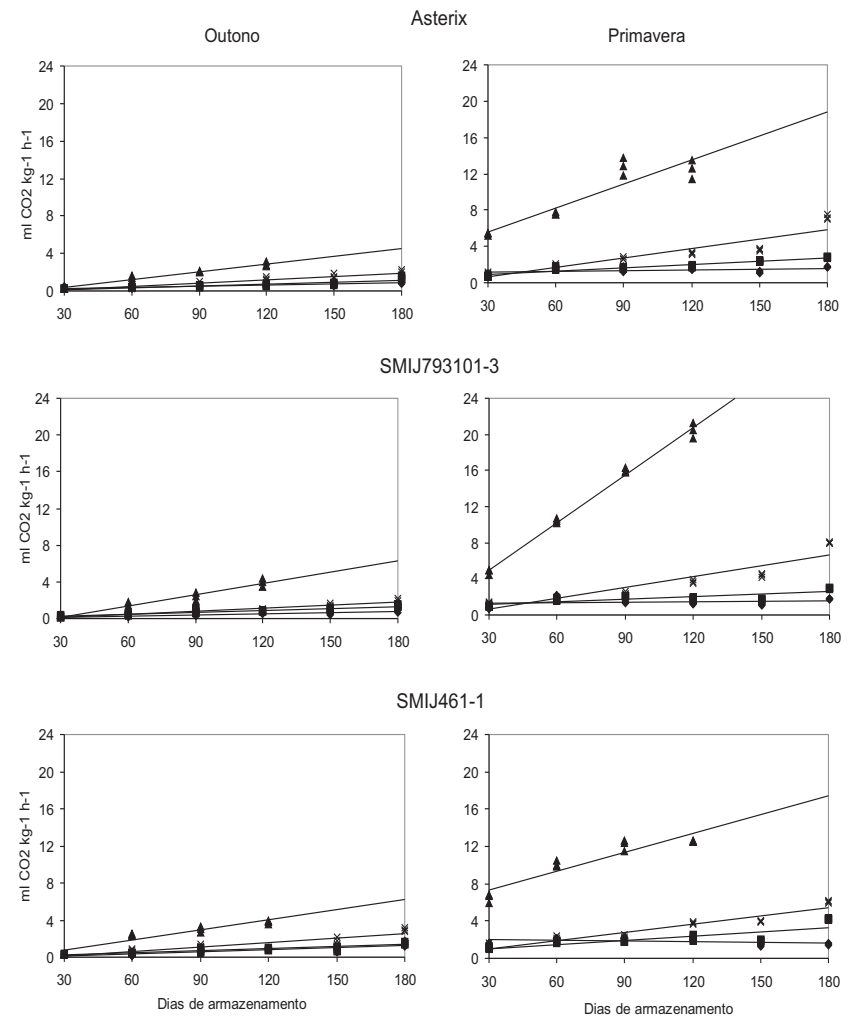

SMIJ461-1

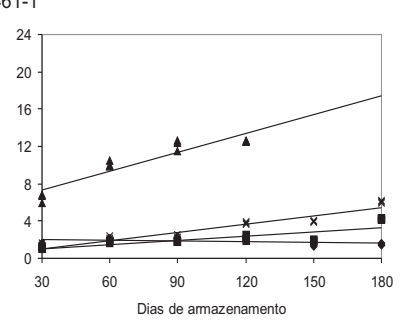

Figura 4. Respiração de tubérculos dos clones Asterix, SMINIA793101-3 e SMIJ461-1 de batata armazenados em diferentes temperaturas durante 180 dias. Santa Maria (RS), 2005. Plantio de outono - Asterix $4{ }^{\circ} \mathrm{C} y=0,1724+0,0036 x$ $\mathrm{R}^{2}=0,76 ; 8{ }^{\circ} \mathrm{C} \mathrm{y}=-0,0824+0,0069 x \mathrm{R}^{2}=0,79 ; 12{ }^{\circ} \mathrm{C} \mathrm{y}=-$ $0,2567+0,012 \times R^{2}=0,87 ; 25{ }^{\circ} \mathrm{C} y=-0,4783+0,029 \times R^{2}=0,96$; SMINIA793101-3 $4{ }^{\circ} \mathrm{C} y=0,0598+0,0043 x R^{2}=0,65 ; 8{ }^{\circ} \mathrm{C}$ $\mathrm{y}=0,0827+0,0067 \times \mathrm{R}^{2}=0,87 ; 12{ }^{\circ} \mathrm{C} \mathrm{y}=-0,2807+0,0115 \mathrm{R}^{2}=0,91$; $25{ }^{\circ} \mathrm{C} y=-1,0567+0,0408 \times R^{2}=0,94$; SMIJ461- $4{ }^{\circ} \mathrm{C} y=-$ $0,1262+0,008 \times R^{2}=0,80 ; 8^{\circ} \mathrm{C} y=-0,0109+0,0076 \times R^{2}=0,85 ; 12{ }^{\circ} \mathrm{C}$ $y=-0,3371+0,0157 \times R^{2}=0,84 ; 25^{\circ} \mathrm{Cy}=-0,3283+0,036 x R^{2}=0,89$. Plantio de primavera - Asterix $4{ }^{\circ} \mathrm{C} y=1,0569+0,0031 \mathrm{x}$ $\mathrm{R}^{2}=0,71 ; 8{ }^{\circ} \mathrm{C} \mathrm{y}=0,4947+0,0125 x \quad \mathrm{R}^{2}=0,91 ; 12{ }^{\circ} \mathrm{C} \mathrm{y}=-$ $0,4071+0,035 \times R^{2}=0,82 ; 25{ }^{\circ} \mathrm{C} y=2,9267+0,0886 \times R^{2}=0,84$; SMINIA793101-3 $4{ }^{\circ} \mathrm{C} y=1,2089+0,002 \times R^{2}=0,53 ; 8{ }^{\circ} \mathrm{C}$ $\mathrm{y}=0,8867+0,0094 \times \mathrm{R}^{2}=0,66 ; 12{ }^{\circ} \mathrm{C} \mathrm{y}=-0,606+0,0402 \times \mathrm{R}^{2}=0,86$; $25{ }^{\circ} \mathrm{C} y=-0,2433+0,1752 x R^{2}=0,99$; SMIJ461- $4{ }^{\circ} \mathrm{C} y=2,084-$ $0,0027 x R^{2}=0,55 ; 8{ }^{\circ} \mathrm{C} y=0,544+0,0155 x R^{2}=0,66 ; 12{ }^{\circ} \mathrm{C}$ $y=0,1969+0,0292 \times R^{2}=0,92 ; 25^{\circ} \mathrm{C} y=5,29+0,0673 \times R^{2}=0,87$.

O armazenamento adequado possibilita minimizar as perdas de quantidade e qualidade dos tubérculos, pois perdas de massa fresca também afetam a qualidade (Hesse, 2005). O sucesso do armazenamento depende da adequada suberização dos tubérculos, um complexo processo bioquímico e fisiológico em que danos físicos são recuperados pelo desenvolvimento de novas células e depósito de suberina e compostos graxos, o que minimiza as perdas de água e limita a penetração de patógenos (OBerg, 2004; Hesse, 2005). Neste experimento, todos os tubérculos utilizados foram submetidos ao mesmo

processo de suberização antes de iniciar os tratamentos. $\mathrm{O}$ armazenamento a $5^{\circ} \mathrm{C}$ minimiza as perdas de massa fresca (Воотн е Sнаw, 1990) e a respiração, o que reduz a produção de calor e $\mathrm{CO}_{2}$ pelos tubérculos (Wiltshire e Совв, 1996; Hesse, 2005). O aumento da perda de massa fresca com a temperatura de armazenamento também pode ser relacionado com a diminuição do período de dormência, pois a brotação está associada com o aumento da respiração dos tubérculos (BоOTH e SHAw, 1990; Hesse, 2005). O incremento da respiração promove a degradação das substâncias de reserva e a transpiração, a perda de água, e ambos os processos são responsáveis pela perda de massa fresca. Portanto, a maior respiração verificada no plantio de primavera provavelmente está associada a maior porcentagem de tubérculos brotados e ao maior número de brotos por tubérculo, pois a respiração é necessária para suprir as necessidades energéticas dos tubérculos (WILTSHIRE е Совв, 1996; Hesse, 2005).

Os resultados deste trabalho confirmam que as condições ambientais de épocas de plantio, principalmente temperatura e fotoperíodo, alteram o período de dormência dos tubérculos, fazendo com que tubérculos produzidos durante a primavera tenham menor dormência do que os produzidos durante o outono. Também confirmam que a redução da temperatura de armazenamento aumenta o período de dormência dos tubérculos e reduz a perda de massa fresca. Portanto, tanto a produção quanto o armazenamento em temperaturas mais elevadas aceleraram o envelhecimento fisiológico dos tubérculos. O início da brotação desencadeia um processo contínuo de aumento da porcentagem de tubérculos brotados e do número de brotos por tubérculo e, em conseqüência, da respiração e da perda de massa fresca, similar para os diferentes clones e épocas de plantio avaliados. Portanto, o armazenamento refrigerado é mais eficaz para reduzir a atividade metabólica dos tubérculos durante o período de dormência do que após o início da brotação. O aumento do período de dormência é necessário para retardar o envelhecimento fisiológico e minimizar as perdas quantitativas e qualitativas. $\mathrm{O}$ aumento da temperatura de armazenamento pode ser utilizado para promover o envelhecimento fisiológico e acelerar a brotação dos tubérculos-semente.

\section{CONCLUSÕES}

1. A época de plantio altera o comportamento fisiológico dos tubérculos durante o armazenamento.

2. $\mathrm{O}$ armazenamento à baixa temperatura $(4 \mathrm{e}$ $\left.8{ }^{\circ} \mathrm{C}\right)$ é eficaz para retardar o envelhecimento fisiológico. 


\section{AGRADECIMENTOS}

Ao Conselho Nacional de Desenvolvimento Científico e Tecnológico (CNPq) pela concessão de bolsa de produtividade em pesquisa para os professores Dilson A. Bisognin, Auri Brackmann e Jerônimo L. Andriolo, bolsa de mestrado para Sergio T. de Freitas e de iniciação científica para Maurício G. Bandinelli. A Coordenação de Aperfeiçoamento de Pessoal de Nível Superior (CAPES) pela concessão de bolsa de mestrado para Douglas R. Muller. A empresa Fockink pelo fornecimento do sistema de monitoramento de temperatura e umidade relativa no interior das câmaras.

\section{REFERÊNCIAS}

ASIEDU, S.K.; ASTATKIE, T.; YRIDOI, E.K. The effect of seedtuber physiological age and cultivar on early potato production. Journal of Agronomy \& Crop Science, Madison, v. 189, p. 176-184, 2003.

BEUKEMA, H. P.; VAN DER ZAAG, D. E. Potato improvement: some factors and facts. Wageningen: International Agricultural Centre, 1979. 224p.

BISOGNIN, D. A. Recomendações técnicas para o cultivo da batata no Rio Grande do Sul e Santa Catarina. Santa Maria: Universidade Federal de Santa Maria, 1996. 64 p.

BOOTH, R.H.; SHAW, R.L. Principios de almacenamento de papa. Lima, Peru: Agropecuária Hernisferio Sur, 1990. 107p.

BURTON, W.G.; VAN, E.S; HARTMANS, K.J. The physics and physiology of storage. In: P. Harris (ed.). The potato crop. London: Chapman \& Hall, 1992. p.608-727.

CALDIZ, D.O.; BROCCHI, G.; ALANIZ, J.; MARCHAN, C. Effects of the physiological age of seed potatoes on tuber initiation and starch and dry matter accumulation. Pesquisa Agropecuária Brasileira, Brasília, v. 31, p. 853-858, 1996.

CALDIZ, D.O.; FERNANDEZ, L.V.;STRUIK, P.C. Physiological age index: a new, simple and reliable index to assess the physiological age of seed potato tubers based on haulm killing date and length of the incubation period. Field Crops Research, Amsterdam, v. 69, p. 69-79, 2001.

CHEONG, J.K.C.W.Y.; GOVINDEN, N. Quality of potato during storage at three temperatures. Disponível em: http:/ / farc.gov.mu/amas98/s73.htm. Acesso em 8 jun.2004.

FONTES, P.C.R.; FINGER, F.L. Dormência dos tubérculos, crescimento da parte aérea e tuberização da batateira. Informe Agropecuário, Belo Horizonte, v.20, p.24-29, 1999.

HARKETT, P.J. External factors affecting length of dormant period in potatoes. Journal of the Science of Food and Agricultural, Barking, v. 32, p. 102-103, 1981.

HESSE, B. Storage management essentials. Potato Storage International, Sevenoaks, v.2, p.18-21, 2005.
NODA, T.; TSUDA, S.; MORI, M.; TAKIGAWA, S.; MATSUURAENDO, C.; SAITO, K.; MANGALIKA, W.H.A.; HANAOKA, A.; SUZUKI, Y.; YAMAUCHI, $H$. The effect of harvest dates on the starch properties of various cultivars. Food Chemistry, Barking, v. 86, n. 1, p. 119-125, 2004.

OBERG, N. Early season - above and beyond. Potato Storage International, Sevenoaks, v.1, p.34-36, 2004.

OLSEN, N. Seed storage - age and performance. Potato Storage International, Sevenoaks, v.1, p.32-33, 2004.

PASTORINI, L.H.; BACARIN, M.A.; TREVIZOL, F.C.; BERVALD, C.M.; FERNANDES, H.S. Produção e teor de carboidratos não estruturais em tubérculos de batata obtidos em duas épocas de plantio. Horticultura Brasileira, Campinas, v. 21, n. 4, p. 660-665, 2003.

REYES, L.F.; MILLER, J.C.J; ZEVALLOS, L.C Environmental conditions influence the content and yield of anthocyanins and total phenols in purple and red-flesh potatoes during tuber development. American Journal of Potato Research, Orono, v. 81, n. 3, p. 187-193, 2004.

SUTTLE, J.C. Posharvest changes in endogenous ABA levels and ABA metabolism in relation to dormancy in potato tubers. Physiologia Plantarum, Lund, v.95, p.233-240, 1995.

WILTSHIRE, J.J.J.; COBB, A.H. A review of the physiology of potato tuber dormancy, Annual Applied Biologists, Harpender, v.129, p.553-569, 1996.

WURR, D.C.E.; ALLEN, E.J. Effects of cold treatments on the sprout growth of three potato varieties. Journal of Agricultural Science, Cambridge, v.86, p. 221-224, 1976. 